\title{
Wombat reproduction (Marsupialia; Vombatidae): an update and future directions for the development of artificial breeding technology
}

\author{
Lindsay A Hogan ${ }^{1}$, Tina Janssen ${ }^{2}$ and Stephen D Johnston ${ }^{1,2}$ \\ ${ }^{1}$ Wildlife Biology Unit, Faculty of Science, School of Agricultural and Food Sciences, The University of Queensland, \\ Gatton 4343, Queensland, Australia and ${ }^{2}$ Australian Animals Care and Education, Mt Larcom 4695, Queensland, \\ Australia \\ Correspondence should be addressed to L A Hogan; Email: lindsay.hogan@uqconnect.edu.au
}

\begin{abstract}
This review provides an update on what is currently known about wombat reproductive biology and reports on attempts made to manipulate and/or enhance wombat reproduction as part of the development of artificial reproductive technology (ART) in this taxon. Over the last decade, the logistical difficulties associated with monitoring a nocturnal and semi-fossorial species have largely been overcome, enabling new features of wombat physiology and behaviour to be elucidated. Despite this progress, captive propagation rates are still poor and there are areas of wombat reproductive biology that still require attention, e.g. further characterisation of the oestrous cycle and oestrus. Numerous advances in the use of ART have also been recently developed in the Vombatidae but despite this research, practical methods of manipulating wombat reproduction for the purposes of obtaining research material or for artificial breeding are not yet available. Improvement of the propagation, genetic diversity and management of wombat populations requires a thorough understanding of Vombatidae reproduction. While semen collection and cryopreservation in wombats is fairly straightforward there is currently an inability to detect, induce or synchronise oestrus/ovulation and this is an impeding progress in the development of artificial insemination in this taxon.
\end{abstract}

Reproduction (2013) 145 R157-R173

\section{Introduction}

Within the Vombatidae, there are three species of wombat: Vombatus ursinus (common wombat, CW), Lasiorhinus latifrons (southern hairy-nosed wombat, SHNW) and Lasiorhinus kreffii (northern hairy-nosed wombat, NHNW). CW and SHNW have a current conservation status of 'least concern', but NHNW is 'critically endangered' (IUCN 2011). The NHNW is one of world's rarest species, with an estimated 138-160 individuals remaining in a remnant population in central Queensland (QLD) and 12 individuals recently reintroduced into an insurance population in southwest QLD (A Horsup 2012, personal communication, NHNW recovery team leader). Since European colonisation, there has been a substantial reduction in the distribution of all wombat species (Horsup 2004, Triggs 2009). The SHNW is now confined to four main population centres in South Australia (SA), while the $\mathrm{CW}$ has almost disappeared from the western half of Victoria (VIC), the Bass Strait Islands as well as from many parts of New South Wales (NSW) where it formerly ranged (Triggs 2009).
CW and SHNW have only been routinely kept in captivity since the 1970s, and NHNW are not currently held within any zoological institution (Jackson 2003). Historically, captive wombats have only bred occasionally and no sustainable breeding programme has ever been established; second generation (F2) breeding has yet to occur (V Nicolson 2012, personal communication, SHNW studbook keeper). When considered as one total population, the Australian ex situ wombat population is unsustainable. The mean annual recruitment rate (since 2003) has been 2.5, while the mean annual loss (via death, exports and releases) has been 7.3, and the population has only survived due do restocking with wild-born individuals (V Nicolson 2012, personal communication). Failure to breed wombats in captivity has been primarily associated with a lack of knowledge of their fundamental reproductive physiology and behaviour, combined with inappropriate husbandry and housing. Captive breeding programmes are likely to play an important role in wombat conservation and given their 'least concern' status and close phylogenetic relationship, the CW and SHNW are valuable 
model species for the development of assisted breeding technologies in the NHNW.

Wombat nocturnalism, fossorialism, difficulties of field capture (for repeated sampling) and reticence to breed in captivity have hindered the study of reproductive biology in this taxon. Nevertheless, since 2002, significant advances have been made in characterising the oestrous cycle (West et al. 2004, Finlayson et al. 2006, Hogan et al. 2010b) and in understanding male seasonality and fertility (Hamilton et al. 2000, Taggart et al. 2005, Hogan et al. 2010a). While studies into the preservation of spermatozoa (Taggart et al. 1998, 2005, MacCallum \& Johnston 2005) and manipulation/control of the oestrous cycle (West 2002, Druery et al. 2007, Finlayson et al. 2007 b) have been attempted, there are still many aspects of wombat reproduction that require further characterisation. The aim of this review is to provide an update on the current knowledge of wombat reproductive biology (highlighting species differences) and to identify where additional research is required in terms of developing reliable artificial breeding technology. Given that there is very limited information on NHNW reproduction, this review will primarily focus on the CW and SHNW.

\section{Reproductive anatomy and morphology}

Table 1 reports a summary of the studies on male and female reproduction in the Vombatidae.

\section{Male gross anatomy}

The gross anatomy of a male CW reproductive system is shown in Figs 1 and 2. Wombat testes are held in a nonpendulous pre-penile scrotum (Fig. 2A), are ellipsoidal in shape and enclosed (with the epididymides) within a non-pigmented tunica vaginalis (Fig. 2B). The epididymis has three distinctive segments (caput, corpus and cauda) with the caput epididymis being loosely attached to the dorsal pole of the testes and cauda epididymis enclosed within a pocket of the tunica vaginalis (Fig. 2C and D). The vas deferens is non-specialised, possesses no ampullae and empties into the prostatic urethra. The disseminate prostate is enclosed in a fibromuscular capsule, is carrot-shaped and consists of three distinct segments (anterior, central and posterior) with the divisions running transversely (Fig. 2E). While there are no seminal vesicles, there are three pairs $(A, B$ and $C)$ of bulbourethral glands (Fig. 1) in close association with the penile crura and urethral bulbs. The flaccid penis is held in an S-bend configuration within a preputial sac adjacent to the cloacal opening and when erect, it is $\sim 100 \mathrm{~mm}$ in length. While the glans penis is bifurcated, the urethra terminates at the base of this bifurcation but extends as a urethral groove along the inner medial aspects of each bifurcation. The penile shaft has small cuticular spines, $\sim 20 \mathrm{~mm}$ distal to the glans penis. The functional significance of these spines is unknown. While penile spines in other mammals (e.g. felids) are sometimes associated with vaginal or cervical stimulation resulting in induced ovulation, there is currently

Table 1 Published information on Vombatidae reproductive anatomy.

\begin{tabular}{|c|c|c|c|}
\hline References & Species & Sex & Anatomical content \\
\hline Shaw (1800) & $\mathrm{CW}$ & $0^{\top}$ & General gross anatomy, including reproductive organs \\
\hline Home (1836) & $\mathrm{CW}$ & q & Reproductive anatomy (anecdotally reported) \\
\hline Owen (1845) & SHNW & $0^{\pi}$ & General gross anatomy (brief comments on reproductive organs) \\
\hline O'Donoghue (1916) & $\mathrm{CW}$ & $q$ & Description of the appearance of the ovaries and ovarian interstitial tissue \\
\hline MacKenzie \& Owen (1919) & $\mathrm{CW}$ & $\begin{array}{l}\text { o } \\
\text { o }\end{array}$ & $\begin{array}{l}\text { Detailed account of the gross anatomy of the reproductive system } \\
\text { Full description of the gross urogenital anatomy }\end{array}$ \\
\hline Pearson (1944) & $\mathrm{CW}$ & 운 & Description of the gross urogenital anatomy \\
\hline Barnett \& Brazenor (1958) & $\mathrm{CW}$ & $0^{\pi}$ & Presence of a rete mirabile in the spermatic cord \\
\hline Hughes (1965) & $\mathrm{CW}$ & $0^{\top}$ & Sperm morphology \\
\hline Brooks et al. (1978) & SHNW & $0^{+}$ & $\begin{array}{l}\text { Full description of the reproductive system; structural and biochemical characteristics of } \\
\text { accessory reproductive glands; sperm morphology }\end{array}$ \\
\hline Barbour (1981) & SHNW & o & $\begin{array}{l}\text { Full description of the reproductive system; histology and histochemistry of accessory } \\
\text { reproductive glands }\end{array}$ \\
\hline Gaughwin (1981) & SHNW & $\begin{array}{l}0 \\
\dot{q}\end{array}$ & $\begin{array}{l}\text { Structural and biochemical characteristics of the reproductive organs } \\
\text { Structural characteristics of the urogenital tract }\end{array}$ \\
\hline Hughes \& Green (1998) & $\mathrm{CW}$ & 우 & Placentation \\
\hline Moritz et al. (1998) & $\mathrm{CW}$ & q & Ovarian and uterine histological changes associated with the oestrous cycle \\
\hline Taggart et al. (1998) & SHNW & 0 & Seminal characteristics \\
\hline Hamilton et al. (2000) & SHNW & 0 & Seasonal change in accessory glands (structure) \\
\hline Breed et al. (2001) & CW & $0^{\pi}$ & Sperm morphology (i.e. the structural organisation of sperm head components) \\
\hline MacCallum (2004) & $\mathrm{CW}$ & $\begin{array}{l}0 \\
\phi\end{array}$ & $\begin{array}{l}\text { Gross anatomy and testicular histology of the reproductive tract and sperm morphology } \\
\text { Examined the urogenital system (i.e. for the development of an Al protocol) }\end{array}$ \\
\hline Taggart et al. (2005) & SHNW & $0^{0}$ & Seasonal changes in the testis, accessory glands and ejaculate characteristics \\
\hline Hogan et al. (2010a) & SHNW & 0 & Seasonal changes in prostate and bulbourethral gland size \\
\hline
\end{tabular}

CW, common wombat (Vombatus ursinus); SHNW, southern hairy-nosed wombat (Lasiorhinus latifrons); NHNW, northern hairy-nosed wombat (L. krefftii); $\mathrm{Al}$, artificial insemination. 


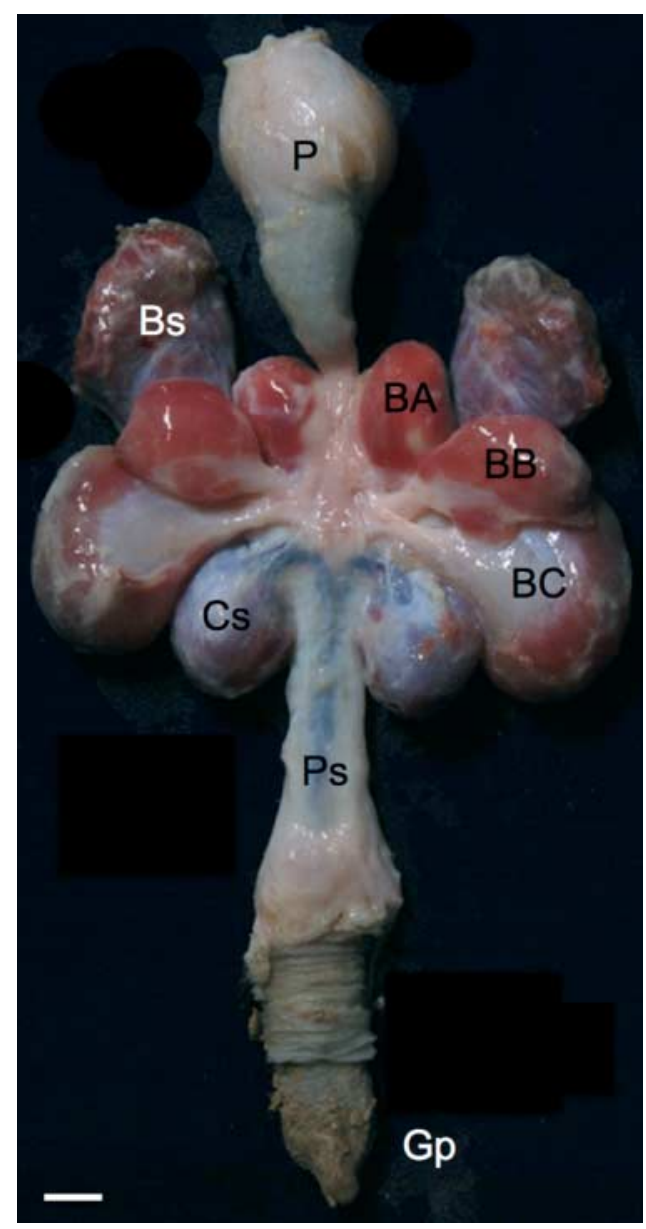

Figure 1 Dissected reproductive tract of a male wombat (Vombatus ursinus). White scale bar $=10 \mathrm{~mm}$. BA, bulbourethral gland $\mathrm{A} ; \mathrm{BB}$, bulbourethral gland $\mathrm{B} ; \mathrm{BC}$, bulbourethral gland $\mathrm{C}$; $\mathrm{Bs}$, bulbospongiosum; Cs, crus penis; Gp, gland penis; P, prostate; Ps, penis.

no evidence to support this pattern in the wombat (Paris et al. 2002, West et al. 2004, Hogan et al. 2010b).

\section{Male micro-anatomy}

Testis

Surprisingly, there has been little description of the micro-anatomy of the wombat testis. Barnett \& Brazenor (1958) noted the presence and fine structure of a rete mirabile in the CW spermatic cord, which was later reconfirmed by MacCallum (2004). The seminiferous epithelial cycle and micro-anatomy of the CW (MacCallum 2004) and SHNW (Oishi et al. 2013) testis have been described. Both species have similar seminiferous tubule mean diameters (CW: $234.0 \pm 4.6 \mu \mathrm{m}$, SHNW: $243.5 \pm 3.9 \mu \mathrm{m})$, possess a high proportion of pre-meiotic (CW: 61.7\%, SHNW: 66.6\%) compared with post-meiotic stages of the seminiferous cycle and have a frequency of cellular associations and dynamics similar to those in other marsupials (Setchell \& Carrick
1973, Lin et al. 2004, Phillips et al. 2008). Interestingly, round spermatid nuclei in vombatids (i.e. koalas and wombats) pass through an elongation phase in late stage I of the cycle to produce a 'rod shaped' uncondensed spermatid nuclei; this morphological stage has not been observed in other marsupials (Oishi et al. 2013). Although a close phylogenetic relationship exists between the koala and the wombat, there are differences in testicular histology between the two species, with the koala displaying a greater proportion of Leydig cells, larger Sertoli cell nuclei, the presence of crystalloids in the Sertoli cell cytoplasm and a highly eosinophilic acrosome (Oishi et al. 2013).

Sperm morphology and spermiogenesis. Hughes (1965) revealed that vombatid spermatozoa were murid-like in morphology and unique amongst the marsupials; the sperm head is 'sickle-shaped' and the neck of the flagellum inserts disto-ventrally. Although the overall sperm head shape of the koala and wombat are similar in form, there are small inter-species differences in the chromatin structural organisation (Breed et al. 2001). Nevertheless, both species have an acrosome that lies within the concavity of the nucleus and from this region a thin segment of acrosome runs both posteriorally and laterally (Breed et al. 2001). Another unusual feature of vombatid spermatozoa is the large degree of heterogeneity in sperm head shape. In the CW this heterogeneity has been defined into six morphotypes and varies from a tight almost circular hook, to a straight or slightly dorsally recurved rod shape (MacCallum 2004). Vombatids also appear to show some heterogeneity in terms of their acrosome morphology (TempleSmith 1994). Although spermiogenesis in vombatids follows a basic marsupial pattern (Temple-Smith 1994), there are a number of distinctive processes that include: formation of a pro-acrosomal granule within the acrosomal vacuole; an uneven condensation of chromatin; a flattening of the nucleus and a ventral neck insertion of the mid-piece into the sperm head, which is thought to account for the variation in sperm head morphology (Brooks et al. 1978, Harding et al. 1987, Harding \& Aplin 1990, Oishi et al. 2013).

Epididymis and sperm maturation. There is currently little information on the gross anatomy and no information on the micro-anatomy of the wombat epididymis. The gross anatomy of the CW epididymis has been described by MacKenzie \& Owen (1919) and MacCallum (2004), but there is only one observation for the SHNW (Brooks et al. 1978). All three studies reported that the cauda epididymis was enclosed within a separate pocket of the tunica vaginalis but no functional significance for this structure has been provided. Wombat spermatozoa are immature when they enter the head of the epididymis and are characterised by the head being only slightly recurved or of an irregular spiral configuration (Brooks et al. 1978); during epididymal maturation there is a marked increase in the recurvature of the sperm head, 
condensation of the accessory cytoplasmic droplet within the hook of the sperm head and rotation of the long axis of the head parallel to that of the flagellum (Hughes 1965). During epididymal transit, wombat spermatozoa show no structural changes to their plasma membrane or cytoskeleton in the mid-piece region; this is in contrast to other marsupial spermatozoa, including to a limited degree the koala (Harding et al. 1979, Harding \& Aplin 1990, Temple-Smith 1994).

\section{Accessory glands}

The segments of the wombat prostate differ in their cytology, tubular histology and histochemistry, and
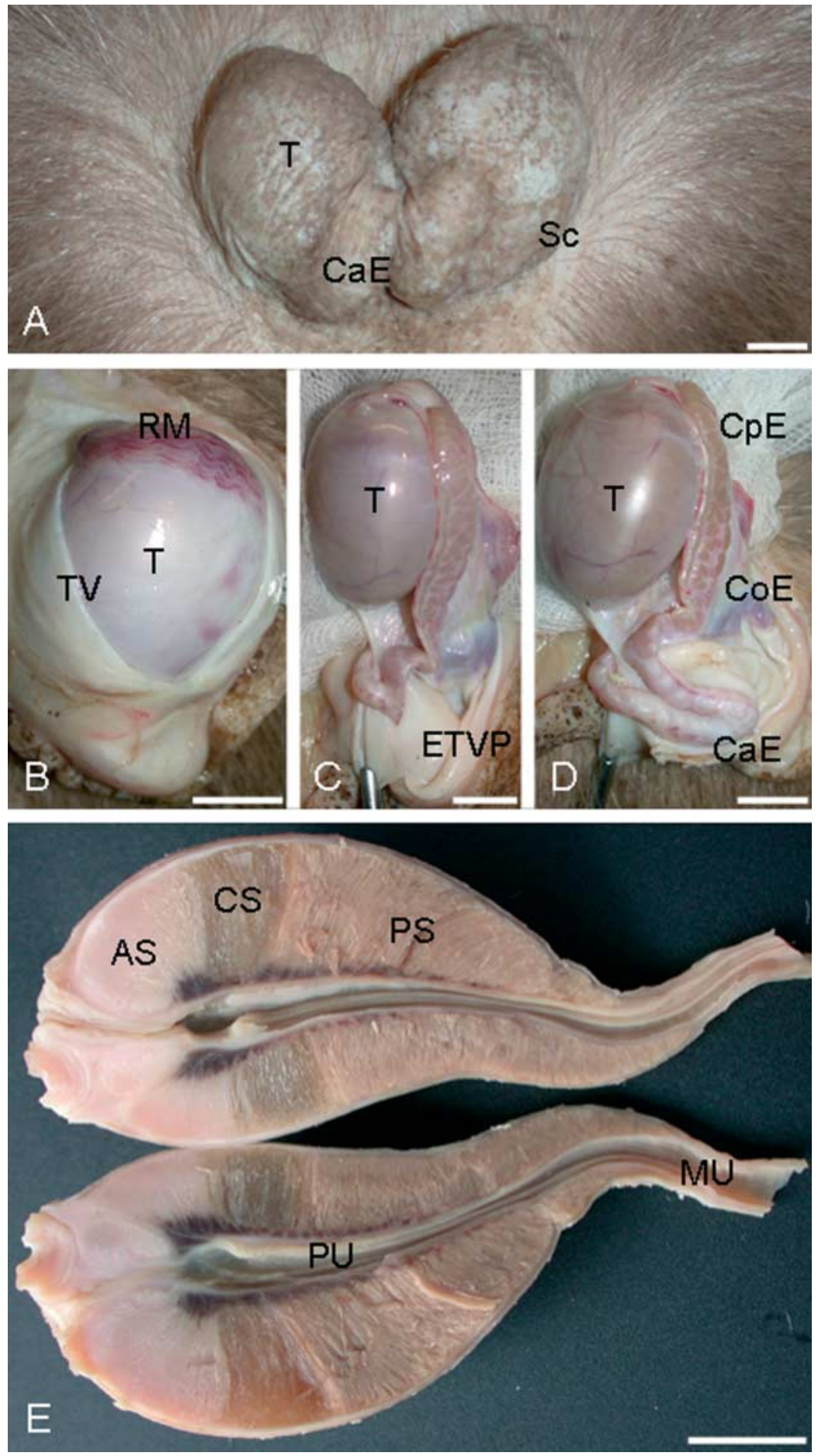

Figure 2 Gross reproductive anatomy of a male wombat (Vombatus ursinus). (A) Non-pendulous scrotum; (B) testis; (C) testis and tunica vaginalis; (D) testis and epididymis; and (E) internal organisation of the prostate. White scale bars $=10 \mathrm{~mm}$. AS, anterior segment; $\mathrm{CS}$, central segment; $\mathrm{CaE}$, cauda epididymis; $\mathrm{CoE}$, corpus epididymis; CpE, caput epididymis; ETVP, epididymal tunica vaginal pouch; MU, membranous urethra; PS, posterior segment; $\mathrm{PU}$, prostatic urethra; $\mathrm{RM}$, rete mirabile; Sc, scrotum; T, testis; TV, tunica vaginalis. Adapted, with permission, from MacCallum (2004). 
secretory products (see review by Barbour (1981)). Prostatic bodies (i.e. secretory globules) occur in the glandular lumen of all segments but are particularly evident in the posterior segment (Brooks et al. 1978). Sorbitol, fructose and glycogen are produced by all three prostate segments, whereas only the central and posterior segments produce glucose and $\mathrm{N}$-acetylhexosamine (Brooks et al. 1978, Tyndale-Biscoe \& Renfree 1987). Iron is another major secretory product of the posterior segment, and acid mucin is also produced by the central segment (Barbour 1981). Wombat bulbourethral glands (three pairs) contain long branched, wide tubular glands surrounded by a layer of connective tissue and skeletal muscle (Brooks et al. 1978). Glands A and B are histologically identical except for the absence of interstitial mast cells from gland B; gland $\mathrm{C}$ is characterised by narrower tubules and larger epithelial cells (Barbour 1981). Gland A secretes primarily protein, gland $\mathrm{B}$ a neutral glycoprotein and gland $\mathrm{C}$ a sialomucin; glands B and C also contain cytoplasmic glycogen in their secretory cells (Barbour 1981).

\section{Female gross anatomy}

The wombat has a rear opening pouch and the teats are reduced to a single pair (Triggs 2009). The juvenile pouch is shallow, with a depth of $\sim 10 \mathrm{~mm}$ and the teats inverted. The adult pouch is $\leq 50 \mathrm{~mm}$ in depth (often more deep laterally on one side), with teats in non-lactating females protruding to a length of $5 \mathrm{~mm}$ (Green \& Rainbird 1987). There has been no description of the wombat mammary gland, nor has the chemical composition of wombat milk been analysed. Mammary gland development only occurs on the teat that is suckled and the teat itself can distend up to $85 \mathrm{~mm}$ long during lactation (Green \& Rainbird 1987). To accommodate the increasing size of the developing pouch young (PY), the pouch enlarges anteriorally, laterally and posteriorally; after weaning, the pouch and recently suckled teat regress (Green \& Rainbird 1987).

Figure 3 shows a dissected female CW reproductive tract from MacCallum (2004). The ovaries are ellipsoidal, dorso-ventrally flattened and enclosed (with the

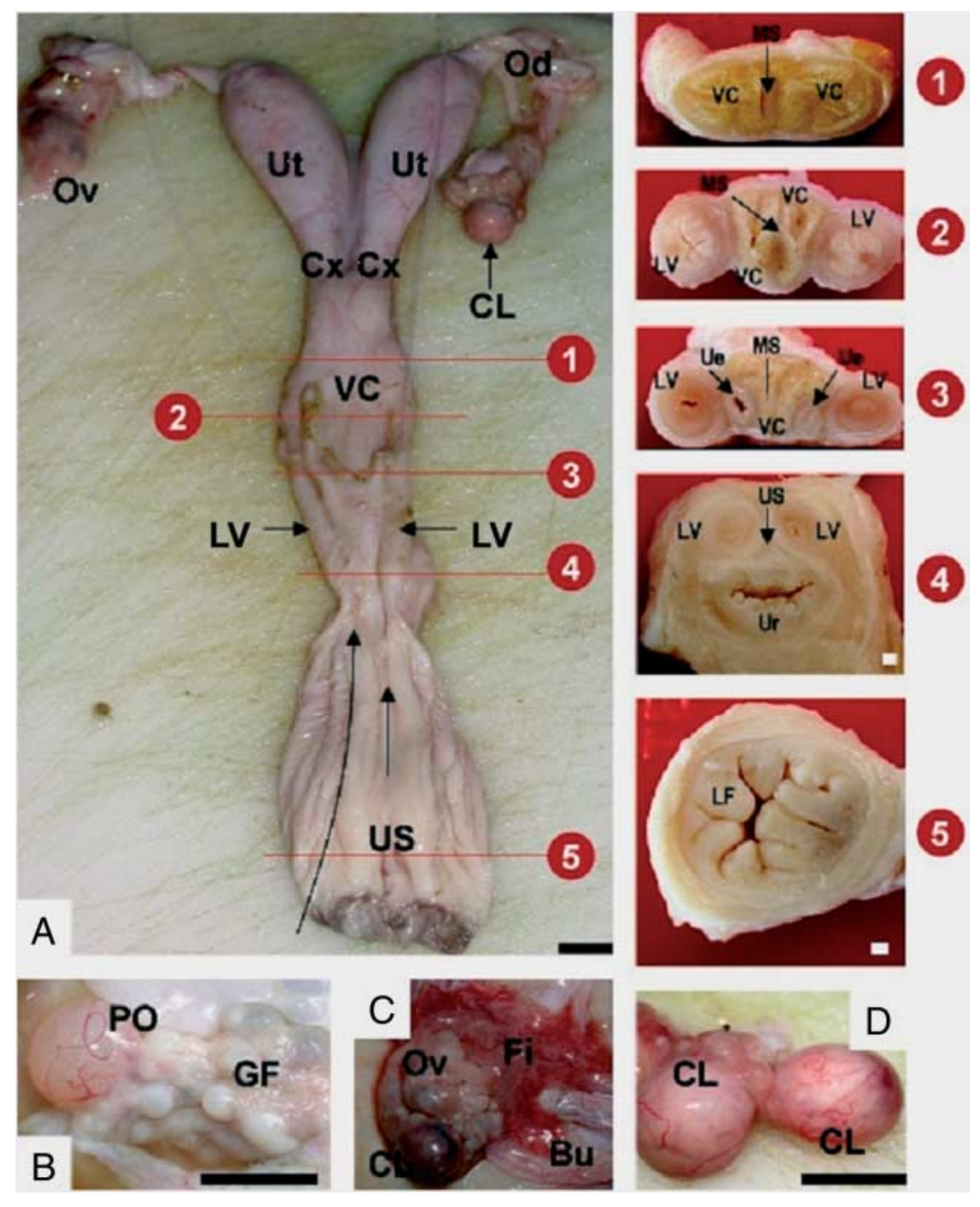

www.reproduction-online.org
Figure 3 (A) Dissected urogenital system of post-luteal female wombat (Vombatus ursinus) with cross sections identifying the relative positions and internal luminal morphology of the different regions of the reproductive tract; (B) pre-ovulatory follicle; (C) corpus luteum; (D) two similar sized corpus luteums on the same ovary. White scale bars $=1 \mathrm{~mm}$. Black scale bars $=10 \mathrm{~mm}$. Bu, bursae; $\mathrm{CL}$, corpora lutea; Cx, cervix; Fi, fimbrae; GF, Graafian follicle; LF, lateral folds of the urogenital sinus; Lv, lateral vaginae; MS, medial septum; Od, oviduct; Ov, ovary; $\mathrm{PO}$, pre-ovulatory follicle; Ue, ureter; Ur, urethra; Us, ovulatory strand; US, urogenital sinus; Ut, uteri; VC, vaginal culs-de-sac. Adapted, with permission, from MacCallum (2004). 
infundibulum and part of the oviduct) within an ovarian bursa. There are two uteri, each with a distinct upper glandular endometrium and lower muscular cervix (Fig. 3A). Both cervixes extend caudally into the vaginal cul-de-sac, which is divided by a medial septum (Fig. 3A). The lateral vaginae enter the upper region of the vaginal cul-de-sac $\sim 20 \mathrm{~mm}$ below the cervical ostia. The caudal portions of the lateral vaginae narrow significantly as they enter the cranial portion of the urogenital sinus. The bladder is connected by a short urethra that opens into the urogenital sinus behind the caudal extremity of the vaginal cul-de-sac. A dorsoventrally flattened, bifid clitoris protrudes from the ventral floor of the urogenital sinus into the cloaca and both the urogenital sinus and rectum open up into the cloaca.

\section{Female ovarian micro-anatomy and folliculogenesis}

The wombat ovary is $\sim 20 \mathrm{~mm}$ in length by $10 \mathrm{~mm}$ in width, depending on the structures present during the different stages of the ovarian cycle (Fig. 3A and C; MacKenzie \& Owen 1919, MacCallum 2004); it is ovoid, dorsally flattened and lobulated in appearance (Fig. 3A and C). The follicular dynamics of the CW ovary have been partially described by O'Donoghue (1916) and Moritz et al. (1998). O'Donoghue (1916) described the micro-anatomy of the mature Graafian follicle and observed that the theca interna of the ovarian follicle was made up of elongated polygonal cells 3-4 layers thick, similar to that of eutherian follicles. Moritz et al. (1998) attempted to link follicular development to ovulation and related changes in ovarian structures to the histology of the rest of the reproductive tract; despite using over 34 reproductive tracts, they were unable to document a female in oestrus or a pre-ovulatory follicle. MacCallum (2004) examined the ovaries of both anoestrous and post-luteal reproductive tracts and noted the occurrence (but not the size) of pre-ovulatory follicles and corpora lutea (Fig. 3B, $\mathrm{C}$ and D).

\section{Pattern of reproduction}

\section{Reproductive strategy}

Wombats have a conservative breeding strategy; there are two teats in the pouch but usually only one young is produced. Gestation is short (CW: 30-33 days (Green \& Rainbird 1987), SHNW: 20-22 days (Crowcroft \& Soderlund 1977)) and occupies a period less than the length of the oestrous cycle (Table 2). Pouch life is long and permanent emergence occurs at 10 months in the CW and at 6-9 months in the hairy-nosed wombats (HNWs) with weaning at 11-13 months (Gaughwin 1981, Boer 1998, Horsup 2004). Female wombats can produce one young in alternate years, the level of reproduction is strongly dependent on annual rainfall and forage availability. CWs and SHNWs become sexually mature at 2-3 years (Mcllroy 1973, Gaughwin 1981), while maturity occurs at $\geq 3$ years in the NHNW (Johnson 1991). The wombat reproductive strategy includes polyoestry, spontaneous ovulation and male/female polygyny (Jackson 2003).

\section{Timing of breeding}

The probability of female SHNWs carrying PY is strongly correlated with plant growth in the previous 6-month period (Gaughwin et al. 1998) and the onset of reproduction is similarly associated with new plant growth (Gaughwin 1981). Likewise, the breeding rate of NHNWs is related to summer rainfall, with most females failing to breed in years with low rainfall (Crossman et al. 1994). These observations suggest a nutritional constraint on female breeding in the HNWs. The precise factors that control male HNW seasonality have not yet been identified. Several studies have demonstrated that peak male reproductive status coincides with the onset of female cyclicity, suggesting that male reproductive activity is activated in response to the female, or that the same environmental cue(s) control both sexes (Gaughwin et al. 1998, Taggart et al. 2005). A widely accepted hypothesis is that the wombat times its breeding so that the weaning of PY coincides with the maximum

Table 2 Wombat oestrous cycle characteristics: a summary of published information.

\begin{tabular}{llllll}
\hline Species & $\begin{array}{l}\text { Mean cycle } \\
\text { length } \text { (days) }\end{array}$ & $\begin{array}{l}\text { Mean LP } \\
\text { length (days) }\end{array}$ & $\begin{array}{l}\text { Mean FP } \\
\text { length (days) }\end{array}$ & Measured by & References \\
\hline CW & $33.0(32-34)$ & - & - & Urogenital cytology & Peters \& Rose (1979) \\
& $55.1(39-61)$ & $28.2(18-37)$ & $25.6(12-30)$ & Faecal progesterone metabolites (RIA) & Paris et al. (2002) \\
& $47.2(35-60)$ & $27.8(18-38)$ & $18.8(5-27)$ & Plasma progesterone & West et al. (2004) \\
& $45.2(32-55)$ & - & - & Vaginal cytology & West et al. (2004) \\
& $50.7(44-57)$ & - & - & Plasma progesterone & MacCallum (2004) \\
SHNW & $50.4(46-56)$ & - & - & Faecal progesterone metabolites (EIA) & (2004) \\
& 41.1 & 27.6 & 13.3 & Faecal progesterone metabolites (RIA) & Paris et al. (2002) \\
& $35.6(35-38)$ & $23.3(16-26)$ & $11.3(10-12)$ & Plasma progesterone & Finlayson et al. (2006) \\
& $31.8(27-38)$ & $20.9(15-31)$ & $11.6(9-15)$ & Faecal progesterone metabolites (EIA) & Hogan et al. (2010b) \\
\hline
\end{tabular}

LP, luteal phase; FP, follicular phase; EIA, enzyme-immunoassay; CW, common wombat (Vombatus ursinus); SHNW, southern hairy-nosed wombat. 
potential growth period of temperate grasses (Mallett \& Cooke 1986, Jackson 2003, Taggart et al. 2005).

NHNWs have a clearly defined breeding season with $83 \%$ of births occurring during the summer months (December-February; Crossman 1988). SHNWs breed a little earlier, with a distinct breeding period between July and December, with most births occurring in October (Gaughwin et al. 1998). Breeding in the CW appears to be much less seasonal with some populations producing young year round. Within their distribution CWs appear to change the time in which females' breed, with mating occurring later in the more southerly regions. As such, the majority of young are born during March-June in northern VIC (Nicolson 1963); June-July in Southern VIC (Presidente 1982); December-March in the highlands of NSW (Mcllroy 1973); year round in Tasmania (TAS; Green \& Rainbird 1987) and year round in eastern VIC, although a peak does occur in summer (West 2002, MacCallum 2004). There are currently no available reproductive seasonality data from the most northern population of CW located in Girraween National Park on the QLD/NSW border.

\section{Breeding dispersal}

A common phenomenon amongst the Vombatidae is female-biased dispersal (Johnson \& Crossman 1991, Banks et al. 2002, Walker et al. 2008). It is proposed that dispersal of adult females after breeding is an indirect form of maternal care, in that bequeathal of the natal burrow to the offspring increases the likelihood of its survival. While there appears to be ecological factors or phylogenetic constraints promoting female dispersal in wombats, male philopatry is common. Male wombats are more genetically similar to local rather than distant males and likely to have been born in the locale in which they are found (Taylor et al. 1997, Banks et al. 2002, Walker et al. 2008); this suggests that the incidence of dispersal by adult or juvenile males is negligible.

\section{Male reproductive cycle}

The CW and SHNW display substantive differences in the degree of male reproductive seasonality. A field study by Mcllroy (1973) revealed seasonal changes in CW testicular diameters, with testes being larger during September-December. MacCallum (2004) found no seasonal variation in body weight, testosterone secretion, testicular volume or sperm quality in either wild or captive CWs. Although not statistically significant, MacCallum (2004) did note that wild CW accessory gland weights were higher in the breeding season when compared with those measured in the nonbreeding season. A lack of a seasonal pattern of reproduction in male CWs is consistent with previous reports of births occurring year round (Green \& Rainbird 1987).
In contrast, wild SHNW males undergo distinct seasonal changes in body weight, semen quality, testicular and accessory gland weight, and androgen concentration (Gaughwin 1981, Taggart et al. 1998, 2005, Hamilton et al. 2000); male reproductive function peaks in August-September and is followed by a marked decline in November. Druery (2004) was the first to monitor the reproductive status of captive SHNW males and discovered that androgen production increased between July and September, but there was no obvious change in testicular size. More recently, Hogan et al. (2010a) provided a more thorough account of captive male SHNW reproductive function and seasonality. Six different reproductive parameters were examined (for 18-months) and a significant seasonal change was detected in plasma testosterone secretion and bulbourethral gland size. Hogan et al. (2010a) concluded that the extent of captive male seasonality was less pronounced than that previously reported for wild SHNWs.

\section{Female reproductive cycle}

Studies on the female reproductive cycle have shown that wombats are polyestrous, with females exhibiting at least to 2-3 cycles per breeding season (West et al. 2004, Finlayson et al. 2006, Hogan et al. 2010b). Oestrous cycle progesterone and oestradiol profiles have been described for the CW and SHNW (Fig. 4A, $\mathrm{B}$ and $\mathrm{C})$. There is only one progesterone peak per cycle, during the luteal phase (LP; Fig. 4A and B), and this peak occurs 17-18 days after oestrus in the CW (West 2002) and 3-9 days after mating in the SHNW (Hogan et al. 2010b). Progesterone secretion/elevation without mating has been frequently observed, confirming spontaneous ovulation in this species (Paris et al. 2002, West et al. 2004, Hogan et al. 2010b). Oestradiol peaks (if observed) occur 3-8 days before the start of the LP and remain elevated for $\sim 8$ days (Fig. 4A; West 2002, Finlayson et al. 2006).

Wombat oestrous cycle length has been well documented (Table 2). In the CW there seems to be a high degree of natural variation between individuals in cycle length and Moritz et al. (1998) have suggested that this is due to a positive correlation with body weight, i.e. as body weight increases so does cycle length. In the SHNW the LP represents $\sim 60 \%$ of the oestrous cycle. A range of studies have found that changes in urogenital cytology, pouch and genitalia morphology and body temperature cannot be used to accurately determine oestrous cycle length, nor indicate the phase of the cycle or the timing of oestrus in wombats. The use of cytology to define the oestrous cycle is problematic as the anatomy of the urogenital sinus makes it difficult to be consistent when swabbing cells from the epithelium of the sinus wall (MacCallum 2004, Finlayson et al. 2006) and sinus length varies between individuals and within 

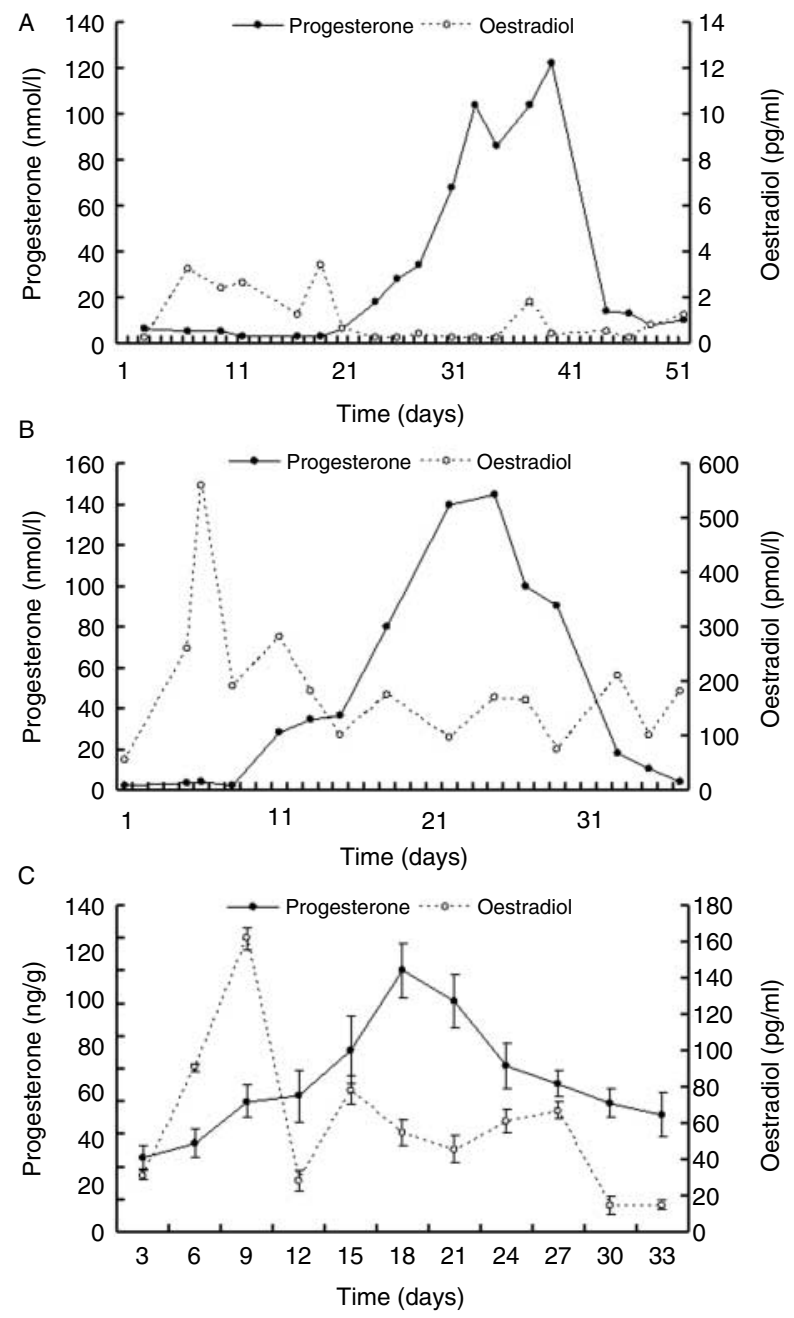

Figure 4 Wombat oestrous cycle progesterone and oestradiol profiles: (A) denotes a cycle from one common wombat (Vombatus ursinus) using plasma hormone measurement. Data from West (2002); (B) denotes a cycle from one southern hairy-nosed wombat (SHNW; Lasiorhinus latifrons) using plasma hormone measurement. Data from Finlayson et al. (2006); (C) denotes the mean ( \pm s.E.M. bars) cycle $(n=12)$ from six SHNWs (L. latifrons) using faecal hormone measurement. Data from Hogan et al. (2010b). Day 1 is the first day of basal progesterone concentrations following the previous luteal phase.

an individual at different stages of the cycle (West et al. 2004). In the case of pouch condition: depth, opening size, wall thickness, degree of cleanliness and/or moisture, and teat length can all provide clues to the reproductive status of the female (i.e. whether cycling or not) but there are no distinct variations directly associated with the oestrous cycle (Peters \& Rose 1979, West 2002, MacCallum 2004). The clitoris and pericloacal region can become swollen and tumescent during different stages of the cycle (Gaughwin 1982, West 2002, Finlayson et al. 2006), but this technique for assessing changes in reproductive status is not reliable, with some researchers not being able to detect any noticeable genitalia changes (MacCallum 2004). The limited scale and small number of replicates used by Peters \& Rose (1979) prevented the drawing of any strong conclusions as to whether body temperature rhythms could be correlated with cyclicity in the CW.

Currently, there is no reliable method for detecting oestrus in wombats. Although several behavioural studies have reported that female wombats become very active at oestrus (Mcllroy 1973, Peters \& Rose 1979, Triggs 2009), a study by Hogan et al. (2010b) indicated that oestrus was not detectable in female SHNWs using continuous observations of physical activity (via movement-sensitive transmitters), as there was no difference in the amount of physical activity recorded during oestrus and anoestrous, nor was there any correlation found between physical activity and the occurrence of reproductive behaviour. Further studies into reliable methods of oestrus detection are urgently required as this specific lack of information has probably been the most significant impediment to successful captive breeding management.

While there has been a significant advance in knowledge of the wombat oestrous cycle over the last decade, there are numerous hormonal, morphological and behavioural aspects of the cycle that are still poorly understood; luteinizing hormone (LH) or follicle-stimulating hormone (FSH) profiles have yet to be documented as has their respective relationship to natural follicular maturation and ovulation. There have also been no definitive studies that link elevated oestradiol concentrations to oestrus behaviour in wombats and as such the factors controlling oestrus are essentially unknown.

\section{Reproductive behaviour}

Even though numerous studies have examined Vombatidae reproductive behaviour (Table 3), oestrus has rarely been observed and appears to be exceptionally short. Peters \& Rose (1979) reported a period of $15 \mathrm{~h}$ during which mating occurred in the CW, while Hogan et al. (2010c) recorded a period of receptivity of $\leq 13 \mathrm{~h}$ in the SHNW. The period of female receptivity typically lasts 24-48 $\mathrm{h}$ in most mammals (Kilen \& Schwartz 1999) and the reason why it is so short in wombats has yet to be determined. Peters \& Rose (1979) first described the oestrus behaviour of wombats as very active (pacing) and aggressive, and since then only two other observations have been published (CW: Boer 1998, SHNW: Hogan et al. 2010c). Both studies reported that the oestrus female attracts the male's attention through a series of pre-copulatory behaviours termed 'attraction actions'. These actions include: 'nudging', where the female makes repeated nose-to-nose, nose-to-flank or flankto-flank contacts with the male; 'rump presentation' where the female presents her urogenital region to the male; and 'frontal displays' where the female digs frantically and/or urinates frequently in front of the 
Table 3 Published information on Vombatidae reproductive behaviour.

\begin{tabular}{lll}
\hline References & Species & Behavioural content \\
\hline Wells (1971) & SHNW & Captive observations of reproduction $(n=5)$ \\
Mcllroy (1973) & CW & Breeding-season-related changes in female behaviour (field study) \\
Crowcroft \& Soderlund (1977) & SHNW & Captive observations of reproduction $(n=3)$ \\
Gaughwin (1978) & SHNW & Following and copulatory behaviour of captive wombats $(n=13)$ \\
Wells (1978) & SHNW & Field observations of male pursuit (of females) and sexual-related vocalisations \\
Gaughwin (1979) & SHNW & Description of flehmen in a captive male $(n=1)$ \\
Brown \& Young (1979) & CW & Male flehmen behaviour and mating in a pair of captive wombats $(n=2)$ \\
Peters \& Rose (1979) & CW & Intermittent observations of reproductive behaviour in captivity; oestrus behaviour \\
Gaughwin (1982) & SHNW & Captive observations of reproduction in wombats at Brookfield Zoo \\
Taylor (1993) & CW & Chase sequences and mating positions of free-ranging wombats \\
Boer (1998) & CW & Full description of reproductive behaviour in a pair of wombats at Hannover Zoo $(n=2)$ \\
Marks (1998) & CW & Courtship and mating in a pair of free-ranging wombats $(n=2)$ \\
Paris et al. (2002) & CW & Flehmen and sniffing behaviour of male wombats at University of Melbourne \\
Stenke (2002) & NHNW & Evidence of courtship in a pair of wombats $(n=2)$ \\
Hughes \& Hughes (2006) & CW & A field observation of daytime courtship and mating in a pair of wombats $(n=2)$ \\
Triggs (2009) & CW & General description of reproductive behaviour in this species \\
Hogan et al. (2010c) & SHNW & Full description of reproductive behaviour in a captive population $(n=12)$
\end{tabular}

$\mathrm{CW}$, common wombat (Vombatus ursinus); SHNW, southern hairy-nosed wombat (Lasiorhinus latifrons); NHNW, northern hairy-nosed wombat (L. krefftii).

male. Whether these behaviours are indicative of oestrus has yet to be determined, but their repetitive nature and high frequency of occurrence just before mating suggests that this is likely.

Comprehensive descriptions of the full suite of wombat courtship-to-mating behaviour are available for the CW (Boer 1998, Marks 1998) and SHNW (Hogan et al. 2010c) and will not be reiterated here. Interestingly, the courtship-to-mating ritual in both species is almost identical and can be divided into six consecutive phases: investigation, attraction, chase, restraint, coitus and recovery. Other similarities include: a long duration of courtship before and guarding following mating; mating being preceded by high levels of male sniffing, parades and pursuits; most mating occurs at night and is carried out within an enclosed space (Table 3). Given the short duration of oestrus and predominate nocturnal mating activity, confirmation of mating success or detection of oestrus for the purposes of artificial insemination (AI) is going to be very challenging in this species; i.e. reliable oestrus detection is going to require 24-h video surveillance along with a teaser male.

Several Australian zoos have an active wombat breeding programme but as yet, none have been able to establish a reliable, self-sustaining programme. Although pairs mate regularly, reports of resultant PY are infrequent suggesting low fertility or inadequate breeding management (MacCallum 2004, Hogan et al. 2010c). Even in cases where mating has been successful, there is a high incidence of PY loss (V Nicolson 2012, personal communication). A number of factors have been reported to contribute to this phenomenon including: individual animal behavioural incompatibility issues (i.e. refusal to mate), poor body condition, diet, reversed social dominance (i.e. female dominant to male), inadequate breeding facilities (e.g. no blind tunnels), lack of space, infertility and failure to learn wombat-specific breeding behaviour due to hand- rearing (Gaughwin et al. 1998, Jackson 2003, MacCallum 2004, Hogan et al. 2010b, 2010c). We must conclude that current understanding of Vombatidae reproductive behaviour, particularly those aspects related to mating success, oestrus prediction and identification are largely inadequate.

\section{Growth and development}

\section{Pre-natal development and parturition}

There are currently no studies on fertilisation biology in the Vombatidae. While Hughes \& Green (1998) describe the pre-natal stages of embryonic development in the $\mathrm{CW}$ before hatching from the shell membrane, no definitive embryonic structures are present until midway through gestation. The wombat exhibits duel placental structures, which include a non-invasive but vascularised chorio-allantois and a yolk-sac; defined as a 'Type 3 ' placental structure according to TyndaleBiscoe \& Renfree (1987). With respect to parturition behaviour, a female CW was observed by Boer (1998) to be 'squatting' on her hindquarters with part of her weight supported by the forelimbs. Entire body tremors, 5-10 s in length, were observed and in-between these tremors the female rolled onto her side and grasped (with one forelimb) the area between the urogenital sinus and pouch opening. While a similar squatting position (Fig. 5) and body tremor was also noted in another CW (M Barnes 2012, personal communication, Dreamworld mammal keeper), this female did not roll onto her side, but instead bent forward and repeatedly tapped and/or kneaded her front paws on the ground. Barnes also noted that the female alternated between the squatting and bent forward positions, all the while vocalising, teeth grinding and body shaking. When squatting, the female made repeated thrusting movements with her hindlimbs, fully extending her hindlimbs for a few seconds (Fig. 5) 

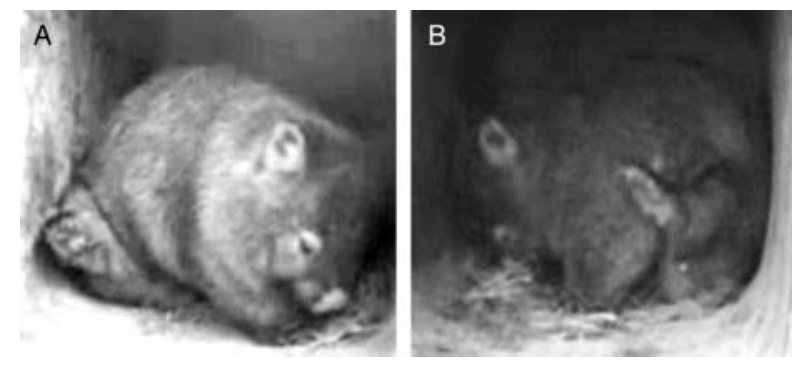

Figure 5 Parturition postures observed in a captive common wombat (Vombatus ursinus). Female is 'squatting' and making repeated thrusting movement with the hindlimbs, fully spreading them and holding them extended for a few seconds (Barnes, unpublished data).

and then releasing muscle tension again. This behaviour went on repeatedly for over an hour. While the birth of the neonate $(\sim 2 \mathrm{~g})$ was not witnessed by Barnes, Boer (1998) noted that following parturition, the neonate $(<10 \mathrm{~min})$ crawled its way from the urogenital opening to the pouch and attached to one of the teats without any maternal assistance.

\section{Pouch development}

Repeated wild female capture is impractical, so as a consequence, wombat PY growth and development charts have been derived from captive-bred and handreared animals only. PY growth curves have been established based on mass and total body length for CWs and SHNWs, and mass and head length for SHNWs (Gaughwin 1982, Boer 1998, Taggart et al. 2007, Triggs 2009). No data on growth and development of PY are currently available for the NHNW. Figure 6 shows the variation between CW and SHNW PY mass growth curves (see review by Jackson (2003)). The growth rate of wombat PY is linear between birth and Day 310, after which growth slows and is best described by a polynomial equation (Taggart et al. 2007). Wild PY cannot be accurately aged using current captive growth curves due to the intrinsic differences between captive vs wild conditions; the mass of wild wombats varies as much as $40 \%$ between seasons and body length is also highly variable between individuals (Taggart et al. 2007, Triggs 2009). Wild PY age is best approximated using physical characteristics (Table 4). There is limited information available on wombat PY development (Table 4) with studies composed of incomplete data based on 1-2 individuals only (e.g. Mcllroy 1973, Crowcroft \& Soderlund 1977, Gaughwin 1982, Presidente 1982). There appears to be a different rate of development between CW and SHNW PY with most physical characteristics in the SHNW developing earlier (Table 4); SHNW ears unfold at 30-60 days, whereas CW ears do not unfold before Day 90. Other aspects of development such as first release of the teat (135-140 vs 150-206 days), permanent pouch emergence
(235-270 vs 240-305 days) and weaning (340-365 vs 345-450 days) also occur earlier in the SHNW (Table 4). It has been suggested that climatic and/or dietary limitations on lactation and growth are less severe in the CW, enabling PY development to proceed at a slower pace (Taggart et al. 2007).

\section{Artificial reproductive technology}

Artificial reproductive technology (ART) has considerable potential for improving the propagation and genetic diversity of wombat populations and has already been explored to a limited extent in the Vombatidae (e.g. sperm cryopreservation; $\mathrm{Al}$; cross-fostering; ovarian hyperstimulation; ovarian tissue xenografting). Despite these advances, practical methods for manipulating wombat reproduction for the purposes of obtaining research material or for artificial breeding are not yet available. One of the major reasons for this is that the precise timing of oestrus and ovulation is not well documented, nor are the hormonal changes associated with these events.

\section{Semen collection and cryopreservation}

Wombat seminal characteristics have been recorded in studies focusing on the monitoring of male fertility and on the development of electro-ejaculation (EJ) and semen cryopreservation techniques (Table 5). EJ techniques in the CW and SHNW were first described by Taggart et al. (1998) and have changed little since. In brief, the male wombat is anaesthetised before a lubricated multipolar rectal probe, with three longitudinally orientated strip electrodes inserted into the rectum. Semen is collected using an electrical stimulation unit and an EJ sequence (three series of $30 \mathrm{~s}$ of stimuli with 3-5 min rest periods between each series (Taggart et al. 1998) or multiple series of $3 \mathrm{~s}$ of stimuli for

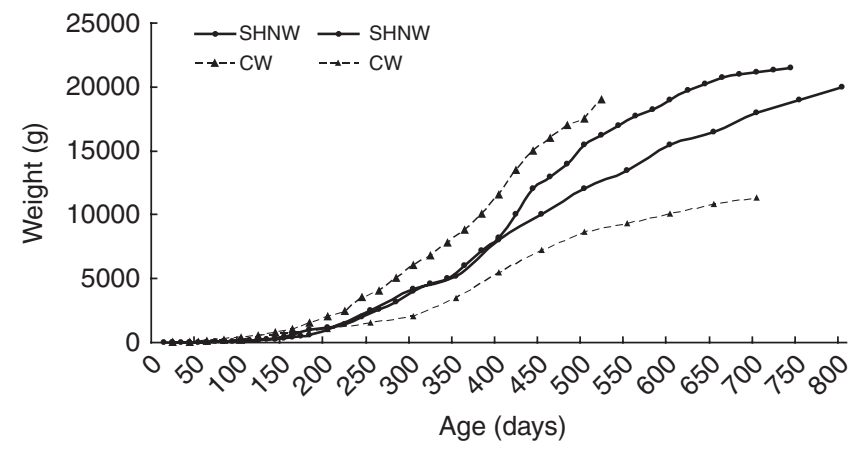

Figure 6 Pouch young growth curves (in body weight) for the common (CW; Vombatus ursinus) and southern hairy-nosed (SHNW; Lasiorhinus latifrons) wombat. Closed circles represent data from Taggart et al. (2007). Open circles and closed triangles represent data from Jackson (2003). Open triangles represent data from Boer (1998). 
Table 4 Pouch young development (in days) in wombats: a summary of published information.

\begin{tabular}{|c|c|c|c|c|c|c|}
\hline Developing features & $\begin{array}{l}\text { CW (Green \& } \\
\text { Rainbird 1987) }\end{array}$ & $\begin{array}{l}\text { CW } \\
\text { (Presidente 1982) }\end{array}$ & $\begin{array}{l}\text { CW } \\
\text { (Boer 1998) }\end{array}$ & $\begin{array}{l}\text { CW } \\
\text { (Triggs 2009) }\end{array}$ & $\begin{array}{l}\text { SHNW } \\
\text { (Gaughwin 1982) }\end{array}$ & $\begin{array}{l}\text { SHNW (Taggart } \\
\text { et al. 2007) }\end{array}$ \\
\hline Vocalisations present & & & & & $\sim 176$ & $\sim 150$ \\
\hline Incisors present & $\sim 112$ & & $\sim 150$ & $\sim 120$ & $90-120$ & 99-107 \\
\hline \multicolumn{7}{|l|}{ Eyes } \\
\hline Closed & $<140$ & $<105$ & $<120$ & $<120$ & $<120$ & $<120$ \\
\hline Lashes & & & 98-105 & $\sim 90$ & & $\sim 110$ \\
\hline Open & $\sim 140$ & $\sim 105$ & $120-155$ & $>120$ & $>120$ & $120-145$ \\
\hline \multicolumn{7}{|l|}{ Ears } \\
\hline Fused & & & $<110$ & $<90$ & & $<30$ \\
\hline Unfolding & & & $110-120$ & $\sim 90$ & $\sim 30$ & $30-60$ \\
\hline \multicolumn{7}{|l|}{ Body fur } \\
\hline None & $<140$ & $<180$ & $<155$ & $<150$ & $<120$ & $<143$ \\
\hline Fine & 140-196 & 180-210 & $155-261$ & 150-180 & & \\
\hline Thick & $>196$ & $>210$ & $>261$ & $>210$ & $180-210$ & $143-210$ \\
\hline Teat & & & & & $>210$ & $>210$ \\
\hline Lips fused & $<84$ & & $<135$ & $<150$ & & $<80$ \\
\hline Lip vibrissae & $\sim 55-60$ & & $90-120$ & & $90-120$ & \\
\hline Lips free & $\sim 84$ & & $\sim 135$ & $\sim 150$ & & 80-92 \\
\hline On/off teat & $\sim 168$ & & $\sim 206$ & $\sim 150$ & & $135-140$ \\
\hline \multicolumn{7}{|l|}{ Pouch status } \\
\hline In & $<168$ & $<255$ & $<255$ & $<180$ & $<180$ & $<160$ \\
\hline In and out & $168-224$ & $255-285$ & $255-270$ & $210-240$ & $180-210$ & $160-210$ \\
\hline Out & $\sim 280$ & $>285$ & $300-305$ & $240-300$ & $\sim 270$ & $235-265$ \\
\hline Weaned & $\sim 350$ & $\sim 345$ & $360-450$ & $360-450$ & $\sim 360$ & $340-365$ \\
\hline
\end{tabular}

CW, common wombat (Vombatus ursinus); SHNW, southern hairy-nosed wombat (Lasiorhinus latifrons).

a total period of 1-2 min (MacCallum \& Johnston 2005)). Spermic ejaculates are recovered following stimulation with between 13 and $30 \mathrm{~mA}$ in the $\mathrm{CW}$ and 10 and $60 \mathrm{~mA}$ in the SHNW, with the percentage of successful semen collections ranging from 49 to $91 \%$ (Taggart et al. 1998, 2005, MacCallum 2004, Johnston et al. 2006). It is inferred in current literature that CWs are easier to EJ than SHNWs (Taggart et al. 2005, Johnston et al. 2006,
Hogan et al. 2010a) and that a better, SHNW-specific rectal probe should be designed in order to obtain a higher frequency of successful EJ attempts in this species. Ejaculates of both species typically have a high percentage of motile sperm (Table 5). MacCallum \& Johnston (2005) have shown that wombat spermatozoa can also be recovered from post-mortem specimens and stored for upwards of 3 days in the intact cauda

Table 5 Wombat seminal characteristics: a summary of published information.

\begin{tabular}{|c|c|c|c|c|c|c|}
\hline Reference & Species & $\begin{array}{l}\text { Ejaculate } \\
\text { volume }(\mathrm{ml})\end{array}$ & $\begin{array}{l}\text { Total sperm } \\
\text { number }\left(10^{6} / \mathrm{ml}\right)\end{array}$ & $\begin{array}{l}\text { Percentage of } \\
\text { motile } \\
\text { spermatozoa }\end{array}$ & $\begin{array}{l}\text { Sperm motility } \\
\text { rating }\end{array}$ & Percentage live \\
\hline \multirow{2}{*}{$\begin{array}{l}\text { Taggart et al. (1998) } \\
\text { (ejaculate) }\end{array}$} & SHNW (wild) & $\leq 7.5$ & $9.0 \pm 6.2$ & 90-95 (PF) & \multirow{4}{*}{$\begin{array}{l}4-5(\mathrm{PF}) \\
2-4(\mathrm{PT}) \\
5(\mathrm{PF}) \\
5(\mathrm{PT})\end{array}$} & \\
\hline & CW (wild) & $\leq 7.5$ & $7.6 \pm 1.6$ & $\begin{array}{l}\text { 90-95 (PF) } \\
70-90(\mathrm{PT})\end{array}$ & & \\
\hline $\begin{array}{l}\text { Bicknell et al. (2001) } \\
\text { (epididymal) }\end{array}$ & CW (wild) & & & 45 (PT) & & \\
\hline $\begin{array}{l}\text { MacCallum et al. (2001) } \\
\text { (epididymal) }\end{array}$ & CW (wild) & & & $\begin{array}{l}60-62 \text { (PF) } \\
12-40 \text { (PT) }\end{array}$ & & $\begin{array}{l}79-81 \text { (PF) } \\
31-56 \text { (PT) }\end{array}$ \\
\hline \multirow{4}{*}{$\begin{array}{l}\text { MacCallum (2004) } \\
\text { (ejaculate) (fast and } \\
\text { slow freezing) }\end{array}$} & CW (captive) & \multirow[t]{6}{*}{$3.9-7.8$} & $3.8-78.5$ & $83.4 \pm 7.3(\mathrm{PF})$ & $3.6 \pm 0.4(\mathrm{PF})$ & $94.3 \pm 2.6(\mathrm{PF})$ \\
\hline & CW (wild) & & $14-75$ & $63.6 \pm 3.2$ (PF) & $3.6 \pm 0.3$ (PF) & $82.8 \pm 3.1(\mathrm{PF})$ \\
\hline & CW (fast) & & & $10-3 \overline{5}(\mathrm{PT})$ & $1.5-3.0(\mathrm{PT})$ & $30-60(\mathrm{PT})$ \\
\hline & CW (slow) & & & 30-70 (PT) & $3-4$ (PT) & 70-90 (PT) \\
\hline \multirow{2}{*}{$\begin{array}{l}\text { MacCallum \& Johnston } \\
\text { (2005) (epididymal) }\end{array}$} & \multirow[t]{2}{*}{ CW (wild) } & & $29.3 \pm 9.9(2-50)$ & 20-80 (PF) & $1-4(\mathrm{PF})$ & 30-90 (PF) \\
\hline & & & & 13-49 (PT) & 1-2 (PT) & 58-72 (PT) \\
\hline \multirow{2}{*}{$\begin{array}{l}\text { Taggart et al. (2005)', } \\
\text { (ejaculate) }\end{array}$} & \multirow[t]{2}{*}{ SHNW (wild) } & $<1.0$ (Jan) & $2.7 \pm 4.4$ (Jan) & $58.3 \pm 30.5$ (Jan) & & \\
\hline & & 3-9 (Sep) & $34.0 \pm 31.5$ (Sep) & $89.8 \pm 10.8$ (Sep) & $4.5 \pm 0.5(\mathrm{Sep})$ & \\
\hline $\begin{array}{l}\text { Johnston et al. (2006), } \\
\text { (ejaculate) }\end{array}$ & CW (wild) & $<1.0$ (Nov) & $4.0 \pm 4.7(\mathrm{Nov})$ & $\begin{array}{l}64.8 \pm 6.9(\mathrm{Nov}) \\
8-84(\mathrm{PT})\end{array}$ & $2.3 \pm 1.3$ (Nov) & \\
\hline
\end{tabular}

PF, pre-freeze; PT, post-thaw; CW, common wombat (Vombatus ursinus); SHNW, southern hairy-nosed wombat (Lasiorhinus latifrons); NHNW, northern hairy-nosed wombat (L. krefftii).

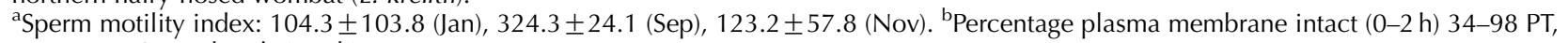
percentage intact heads (0-2 h) 55-91 PT. 
epididymides if the tissue is stored at $4{ }^{\circ} \mathrm{C}$ in a TCF $(3.0 \mathrm{~g}$ Tris buffer, $1.7 \mathrm{~g}$ citric acid, $1.25 \mathrm{~g}$ fructose) buffer.

There have been numerous successful attempts to cryopreserve both cauda epididymal and ejaculated wombat spermatozoa (Table 5). Interestingly, wombat spermatozoa (like those of most other marsupials) do not appear to exhibit susceptibility to cold shock (Miller et al. 2004). As a result, wombat sperm cryopreservation diluents do not necessarily require the addition of egg yolk, but they do require a high concentration of glycerol in order to obtain adequate post-thaw survival. The cryopreservation success of wombat sperm is remarkable, with post-thaw motilities of $\geq 80 \%$ being regularly achieved in both species (Table 5). The most common way of cryopreserving wombat semen is in straws that are frozen in liquid nitrogen, but MacCallum \& Johnston (2005) have also been successful at using a pelleting technique on dry ice. A higher degree of post-thaw survival is achieved when spermatozoa are frozen using a slow $\left(-6^{\circ} \mathrm{C} / \mathrm{min}\right.$ to $100{ }^{\circ} \mathrm{C}$ in a programmable freezer) rather than fast $(3 \mathrm{~cm}$ above liquid nitrogen for $30 \mathrm{~min}$ before being plunged into liquid nitrogen) rate of freezing (MacCallum 2004, Johnston et al. 2006). The main cryoprotectant medium used is a TCF buffer with egg yolk (15\%) and glycerol (8 or $14 \%$ ). Other cryoprotectants used include Krebs-HenseleitRinger base ( $17 \%$ glycerol), Triladyl ( $7 \%$ glycerol), $0.2 \mathrm{M}$ trehalose $(8 \%$ glycerol) and Tris-citrate-glucose buffer with $7.5 \%$ egg yolk and $14 \%$ glycerol (Taggart et al. 1998, Bicknell et al. 2001, MacCallum et al. 2001, Johnston et al. 2006). While cryobiological studies have examined the physio-chemical tolerances and biophysical properties of vombatid spermatozoa (MacCallum 2004, Miller et al. 2004, Johnston et al. 2006), the fertility of freshly collected or cryopreserved wombat sperm has yet to be tested.

\section{Artificial insemination}

Successful Al protocols have only been developed in two marsupials: the koala and tammar wallaby. Contributing factors to the success of $\mathrm{Al}$ in the koala is that oestrus is easily detected and that ovulation can be induced (Johnston et al. 2003). In the tammar wallaby, birth and post-partum oestrus can be tightly synchronised by the removal of PY and ovulation is quite predictable, thus facilitating successful Al (Paris et al. 2005). As there are no reliable methods of oestrus detection, induction or synchronisation in the Vombatidae, the development of a successful Al protocol in wombats has been severely hindered. Druery (2004) attempted to determine the optimal timing for insemination in wombats by testing whether laparoscopy or transabdominal ultrasonography could be used to detect the presence of the pre-ovulatory follicle; these techniques were unsuccessful due to the opaqueness of the ovarian bursa (which obscured the ovary). Given the structural similarity of koala and wombat reproductive anatomy, it is very likely that the methodology used for koala Al would be suitable for wombats. Recently (2012), Australian Animals Care and Education, Inc. (AACE; Mount Larcom, Queensland, Australia) in a joint research project with The University of Queensland (Gatton, Queensland, Australia) conducted a preliminary $\mathrm{Al}$ in two SHNWs using the same catheter design used for the koala (Johnston et al. 2003), but using frozen-thawed wombat caudal epididymidal spermatozoa with a post-thaw motility of $\sim 80 \%$. Using a vasectomised teaser male to detect oestrus in the female, two females were inseminated but no offspring were produced. Al experiments will continue into 2013 but using fresh EJ semen and close observation of oestrus using video surveillance. The AACE facility has over 20 wombats in its care and this large number will allow for more controlled experiments. Some of these females have recently been trained to urinate on demand so that samples can be analysed for hormone metabolites; this will be particularly useful as oestradiol metabolite measurement from SHNW faeces has not been instructive for monitoring oestrous cycle activity (Hogan et al. 2010b).

\section{PY removal and cross-fostering}

Cross-fostering is an ethically challenging conservation technique. While it has the capacity to rapidly accelerate breeding and recruitment, the proliferation of a small captive group of animals can quickly lead to increased levels of inbreeding and/or over-representation of the genetics of a particular individual. This technique also poses a significant ethical issue, as it requires that the progeny of the non-threatened species to be killed, allowing the mother to raise the endangered young. Previous successes in other endangered marsupials (see review by Taggart et al. (2010)) and the poor breeding/ recruitment of the NHNW merit the future development of PY isolation and cross-fostering techniques in the Vombatidae. Some of the ethical concerns associated with this technology could be reduced if oestrus synchronisation procedures, that allow the timed transfer of NHNW PY to CW or SHNW foster mothers at the appropriate stage of the reproductive cycle, are successfully developed. Nevertheless, it would still be a very brave animal manager who would make the decision to transfer a NHNW PY to a foster mother, in preference to allowing it to develop naturally.

Initially, Finlayson et al. (2007a) demonstrated the ability of female SHNWs to produce additional offspring in the same breeding season if a PY was lost or removed at an early stage of development. Thereafter, Finlayson et al. (2007b) demonstrated successful PY isolation and intra-species fostering in the SHNW. PY ranging in age from 16 to 146 days were isolated from the pouch (8-h at $23{ }^{\circ} \mathrm{C}$ and $100 \% \mathrm{RH}$ ) and successfully fostered between adult females. Females recaptured $4-11$ months later 
were still carrying the fostered PY or showed evidence of late lactation on the same teat that the fostered PY was originally attached to. Clearly, accelerated breeding through PY transfer is theoretically possible but further knowledge, leading to reliable captive husbandry and manipulation of the oestrous cycle, first needs to be established.

\section{Ovarian hyperstimulation}

Druery et al. (2005) and West et al. (2007) have shown that ovulation occurs $25-26$ and $36-45 \mathrm{~h}$ after LH administration in hormonally pre-treated CWs and SHNWs respectively. Improved ovulations rates and oocyte yields have also been achieved in both species following hormonal stimulation (West et al. 2003, 2007, MacDonald et al. 2006, Druery et al. 2007). In general, multiple administrations of $\mathrm{FSH}$ are required to stimulate follicular maturation, whilst a single $\mathrm{LH}$ injection is then required to induce ovulation of the recruited follicles. However, reproductive status before hormonal treatment does appear to affect stimulation outcomes, e.g. a higher production of large follicles and recovery of metaphase II (MII) oocytes occur when treatment is commenced early in the follicular phase of the natural oestrous cycle (Druery et al. 2007). Additionally, MII oocytes have only been collected from cycling adults or adults following PY removal (West et al. 2007). Only a low percentage $(\sim 14 \%)$ of oocytes have been reported to complete maturation to the MII stage (most are MI) following hormonal stimulation (Druery et al. 2007, West et al. 2007) indicating that current hormone dose rates and/or recovery times are not optimal. A major drawback of ovarian hyperstimulation in wombats is that ovary harvesting from cull specimens is presently required for the confirmation of stimulation effects. Druery et al. (2005) found that ultrasonographic imaging could not be used to confirm ovulation or the number of follicles in stimulated ovaries, while West et al. (2007) discovered that wombat oocyte recovery via laparoscopy was impractical.

\section{Oocyte maturation}

In vitro maturation (IVM) and ICSI on CW oocytes have been attempted; it appears that immature oocytes generated either naturally or by superstimulation can be matured in culture. Cleary et al. (2003b) used $20 \mathrm{nM}$ HEPES-buffered EMEM handling medium to culture oocytes and after $60 \mathrm{~h}, 34 \%$ matured to the MII stage. Similarly, $16 \%$ of oocytes cultured in TCM-199 medium matured to MII as indicated by the presence of a polar body (West 2002). The low maturation rates indicate that culture conditions will need to be further refined in order to optimise IVM. Maturation rates were greater in oocytes collected from follicles $>2 \mathrm{~mm}$ in size but were not affected by the presence of cumulus cells (Cleary et al. 2003b). Future studies should investigate follicular size and the ability of resultant oocytes to mature in vitro. Oocyte IVF has been demonstrated in the CW, with several MII oocytes cleaving to the 2, 6 or 8 cell stage, 36-48 h following ICSI (West 2002, West et al. 2007); however, most of the injected oocytes $(89 \%)$ degenerated following ICSI and culture. Failure of ICSI to fertilise MII oocytes has been attributed to factors such as oocyte viability, sperm preparation, the ICSI protocol and subsequent culture conditions (West 2002). There is still much to learn before IVM and IVF becomes a reality in the propagation of wombats and in light of both techniques being highly invasive, it is our opinion that the current focus of assisted reproductive technology needs to be on the development of ovulation induction, $\mathrm{Al}$ and $\mathrm{PY}$ transfer. The later techniques are ideally suited to the natural reproductive biology of the wombat, whereas the more invasive studies can be used for the purposes of gamete recovery from postmortem animals or a better understanding of wombat fertilisation biology.

\section{Ovarian tissue xenografting}

Xenografting of ovarian tissue is an advanced ART that can be used to allow growth and recovery of oocytes from cryopreserved ovarian tissue of females that die or are unable to reproduce naturally. In the initial xenografting study (Wolvecamp et al. 2001), CW ovarian tissue was grafted to the kidney capsule of immunocompromised rats and the follicles are allowed to grow to the preantral stage; the nude rat model was unable to support follicle development past the preantral stage (Wolvecamp et al. 2001). Cleary et al. (2003a) then investigated whether an alternative recipient would allow further follicular development and found that xenografting of CW ovarian tissue to immunocompromised mice resulted in follicular development to the antral stage. Immature oocytes were recovered from these antral follicles but failed to develop to MII after IVM (Cleary et al. 2003a). Graft recovery rates and follicular development were higher in ovarian tissue grafted under the kidney capsule, compared with grafts to subcutaneous sites, possibly because of more rapid revascularisation (Cleary et al. 2003a). Later, Cleary et al. (2004) showed that: ovarian tissue can develop to the antral stage when xenografted to male recipient mice; removal of the female recipient's ovaries accelerated follicle development and that no follicular growth occurs in xenografted ovarian tissue from PY or subadult $\mathrm{CW}$ females. As no oocytes were mature at the time of collection or after a period of IVM, it still remains unclear which conditions are best suited to generating viable oocytes from wombat ovarian xenografts (Cleary et al. 2004). 


\section{Future directions}

Future research directions for the development of ART in wombats should initially focus on understanding environmental, social, physical and nutritional influences on mating, fertility and reproductive success. Identification of the requirements vital to the successful breeding of wombats in captivity is of the utmost importance. Until PY can be produced on a regular basis (in captivity) there will be limited opportunity to further investigate topics like fertilisation, embryo development, parturition and cross-fostering. In addition, natural rather than artificial breeding is always preferable, as this ensures that wombats learn and exhibit normal species-specific sexual and parental behaviours. Obtaining a self-sustaining captive wombat population has proven difficult to date and as such knowledge of the physiology, endocrinology and behaviour of wombat reproductive events needs to be rapidly improved. Due to the intrinsic limitations associated with conducting studies within zoological institutions (e.g. low animal numbers, differing husbandry and management, unavoidable anthropomorphic impacts on behaviour, etc.) we also suggest the need for more dedicated 'wombat breeding and research centres', like that currently in development at AACE. Once sufficient animals and captive facilities are available, there will no doubt be a rapid acceleration in wombat breeding success.

While there has been a reduction in wombat population numbers, enough to prompt the Australian government to set in place and enforce legislation to actively protect this taxon in the wild, there are still a number of small CW and SHNW meta-populations that are regularly culled under mitigation permits (in areas where these animals impact agricultural practices or cause structural damage to buildings; Temby (1993)). While unpleasant, these mitigation programmes currently provide unique opportunities to investigate the reproductive anatomy and physiology of wombats that would not otherwise be possible; thus every effort must be made to use this extremely valuable reproductive material. Information gained could then be fed back into improving captive breeding programmes or used to develop and refine ART for the critically endangered NHNW.

Only after we can reliably and repeatedly breed wombats in captivity should we then switch our research emphasis to the development of more advanced forms of ART. Initially, research should centre on the development of $\mathrm{Al}$ and $\mathrm{PY}$ transfer techniques, as the natural biology of the animals (e.g. exceptional post-thaw sperm motilities and production of a second PY following removal of the first) can be capitalised upon and these techniques are far less invasive. The ability to artificially manipulate and/or enhance wombat reproduction will have significant applications, the most important being aiding the recovery of the critically endangered NHNW. Despite an ongoing recovery programme for the NHNW (over the last two decades) it has been suggested that natural breeding, even in conjunction with habitat protection and restoration, may not be able to guarantee the survival of this endangered marsupial (Horsup 2004). While we hope that is not the case, it is important at the very least, to be proactive and develop ART as these techniques may, in the future, be the only way to protect the NHNW gene pool from further loss and at the same time help to propagate a sustainable captive population from which individuals could be reintroduced back into the wild.

Previous central QLD NHNW population monitoring has revealed that this population: i) is highly skewed towards males with only 35 females (and as few as 25 breeding) being present in the population (Horsup 2004); and ii) during years of average-to-above rainfall has $50-75 \%$ of adult females breeding (Crossman et al. 1994). Given that females can only produce one young every 2 years, a reasonable estimated annual recruitment rate (during optimal conditions) for this population ( $n=138-160)$ would be about 6-9. However, the NHNW occupies an arid habitat within QLD with a high drought frequency, and most females ( $\geq 75 \%)$ will fail to breed in years with low rainfall (Crossman et al. 1994). During low-rainfall conditions, the annual recruitment rate for this population would mostly probably be $0-3$. It is here that we see the case for enhancing the breeding success of the NHNW and development of ART is a vital approach towards providing NHNW population support.

\section{Declaration of interest}

The authors declare that there is no conflict of interest that could be perceived as prejudicing the impartiality of the review.

\section{Funding}

This research did not receive any specific grant from any funding agency in the public, commercial or not-for-profit sector.

\section{Acknowledgements}

The authors wish to thank Ms Catriona MacCallum for the release of photographs taken during her master's degree for publication in this review.

\section{References}

Banks SC, Skerratt LF \& Taylor AC 2002 Female dispersal and relatedness structure in common wombats (Vombatus ursinus). Journal of Zoology 256 389-399. (doi:10.1017/S0952836902000432) 
Barbour RA 1981 Histology and histochemistry of the accessory reproductive glands in the male hairy-nosed wombat (Lasiorhinus latifrons). Histochemistry 72 133-148. (doi:10.1007/BF00496788)

Barnett CH \& Brazenor CW 1958 The testicular rete mirabile of marsupials Australian Journal of Zoology 6 27-32. (doi:10.1071/ZO9580027)

Bicknell C, Wolvecamp MJC \& Shaw J 2001 Development of a simple cryopreservation protocol for wombat sperm. Theriogenology $\mathbf{5 5} 300$ (abstract). (doi:10.1016/S0093-691X(00)00457-X)

Boer M 1998 Observations on reproduction in the common wombat (Vombatus ursinus) in captivity. In Wombats, pp 129-148. Eds RT Wells \& PA Pridmore. Chipping Norton: Surrey Beatty and Sons.

Breed WG, Leigh CM \& Ricci M 2001 The structural organization of sperm head components of the wombat and koala (suborder: Vombatiformes): an enigma amongst marsupials. Journal of Anatomy 198 57-66. (doi:10. 1046/j.1469-7580.2001.19810057.x)

Brooks DE, Gaughwin MD, Mann M \& Mann T 1978 Structural and biochemical characteristics of the male accessory organs of reproduction in the hairy-nosed wombats (Lasiorhinus latifrons). Journal of the Zoological Society of London 201 191-207.

Brown GD \& Young G 1979 Wombats - amiable native lawnmowers. Australian Natural History 20 279-285.

Cleary ML, Paris MCJ, Shaw J, Jenkin G \& Trounson AO 2003a Effect of ovariectomy and graft position on cryopreserved common wombat (Vombatus ursinus) ovarian tissue following xenografting to nude mice. Reproduction, Fertility, and Development 15 333-342. (doi:10.1071/ RD03063)

Cleary ML, West M, Shaw J, Jenkin G \& Trounson AO 2003b In vitro maturation of oocytes from non-stimulated common wombats. Reproduction, Fertility, and Development 15 303-310. (doi:10.1071/ RD03042)

Cleary ML, Shaw JM, Jenkin G \& Trounson AO 2004 Influence of hormone environment and donor age on cryopreserved common wombat (Vombatus ursinus) ovarian tissue xenografted into nude mice. Reproduction, Fertility, and Development 16 699-707. (doi:10.1071/ RD04054)

Crossman DG 1988 Population ecology and diet of the northern hairynosed wombat (Lasiorhinus krefftii (Owen)). Research Report to the World Wildlife Fund Australia for Project 64. p74. Rockhampton, Queensland, Australia: Queensland National Parks and Wildlife Service.

Crossman DG, Johnson CH \& Horsup AB 1994 Trends in the population of the northern hairy-nosed wombat (Lasiorhinus krefftii) in Epping Forest National Park, Central Queensland. Pacific Conservation Biology 1 141-149.

Crowcroft P \& Soderlund R 1977 Breeding of wombats (Lasiorhinus latifrons) in captivity. Zoological Garten 47 313-322.

Druery GV 2004 Development of assisted breeding techniques in the Southern hairy-nosed wombat (Lasiorhinus latifrons). Faculty of Arts, Health and Science, PhD Thesis, pp 256. Rockhampton: Central Queensland University.

Druery GV, Rival MD, Taggart DA, Shimmin GA, Horsup AB, Temple-Smith PD, Paris DB \& Paris MCJ 2005 Timing of ovulation in the gonadotrophin-stimulated Southern hairy-nosed wombat, Lasiorhinus latifrons. Reproduction, Fertility, and Development 17246 (abstract). (doi:10.1071/RDv17n2Ab191)

Druery GV, Shimmin GA, Taggart DA, Temple-Smith PD, Breed WG, McDonald CH, Finlayson GR \& Paris MC 2007 Ovarian follicular superstimulation and oocyte maturation in the anoestrous Southern hairy-nosed wombat, Lasiorhinus latifrons. Animal Reproduction Science 99 363-376. (doi:10.1016/j.anireprosci.2006.06.011)

Finlayson GR, Shimmin G, Taggart D, Skinner J, Gilmore A \& Paris MC 2006 Oestrous cycle of captive Southern hairy-nosed wombats (Lasiorhinus latifrons) in South Australia, Australia. Animal Reproduction Science 95 295-306. (doi:10.1016/j.anireprosci.2005.10.001)

Finlayson GR, Taggart D, Shimmin G, White CR, Dibben R, Steele VR, Paris MC \& Temple-Smith PD 2007a Pouch removal and return to oestrous in wild Southern hairy-nosed wombats (Lasiorhinus latifrons). Animal Reproduction Science 100 216-222. (doi:10.1016/j.anireprosci. 2006.09.013)

Finlayson GR, Taggart DA, Shimmin GA, White CR, Steele VR, Paris MCJ \& Temple-Smith PD 2007b The application of intra-species fostering techniques to the Southern hairy-nosed wombat, Lasiorhinus latifrons. Pacific Conservation Biology 13 259-263.
Gaughwin MD 1978 The hairy-nosed wombat (Lasiorhinus latifrons) in captivity. Honours Thesis, pp 47. Adelaide South Australia: University of Adelaide.

Gaughwin MD 1979 The occurrence of flehmen in a marsupial - the hairynosed wombat (Lasiorhinus latifrons). Animal Behaviour 27 1063-1065. (doi:10.1016/0003-3472(79)90054-X)

Gaughwin MD 1981 Socio-ecology of the hairy-nosed wombat (Lasiorhinus latifrons) in the Blanche Town region of South Australia. PhD Thesis, pp 141. Adelaide, South Australia: University of Adelaide.

Gaughwin MD 1982 Southern hairy-nosed wombat (Lasiorhinus latifrons): its maintenance, behaviour and reproduction in captivity. In The Management of Australian Mammals in Captivity, pp 144-154. Ed DD Evans. Victoria: Australian Mammal Society.

Gaughwin MD, Breed WG \& Wells RT 1998 Seasonal reproduction in a population of Southern hairy-nosed wombats (Lasiorhinus latifrons) in the Blanchetown region of South Australia. In Wombats, pp 109-112. Eds RT Wells \& PA Pridmore. Chipping Norton: Surrey Beatty and Sons.

Green RH \& Rainbird JL 1987 The common wombat Vombatus ursinus (Shaw 1800) in Northern Tasmania - Part 1. Breeding, growth and development. Records of the Queen Victoria Museum 91 1-19.

Hamilton RA, Stanton PG, O'Donnell L, Steele VR, Taggart DA \& Temple-Smith PD 2000 Determination of seasonality in Southern hairynosed wombats (Lasiorhinus latifrons) by analysis of faecal androgens. Biology of Reproduction 63 526-531. (doi:10.1095/biolreprod63. 2.526)

Harding HR \& Aplin KP 1990 Phylogenetic affinities of the koala (Phascolarctidae; Marsupialia): a reassessment of the spermatozoal evidence. In Biology of the Koala, pp 1-31. Eds AK Lee, KA Handasyde \& GD Sanson. Sydney, Australia: Surrey Beatty and Sons.

Harding HR, Carrick FN \& Shorey CD 1979 Special features of sperm structure and function in marsupials. In Spermatozoon, pp 289-303. Eds DW Fawcett \& JM Bedford. Baltimore-Munich: Urban and Schwarzenburg.

Harding HR, Carrick FN \& Shorey CN 1987 The affinities of the koala Phascolarctos cinereus (Marsupialia: Phascolarctidae) on the basis of sperm ultra structure and development. In Possums and Opossums: Studies in Evolution, pp 353-364, Ed M Archer. Sydney, Australia: Surrey Beatty and Sons.

Hogan LA, Phillips CJC, Horsup AB, Keeley T, Nicolson V, Lisle A, Janssen T \& Johnston SD 2010a Monitoring male Southern hairy-nosed wombat (Lasiorhinus latifrons) reproductive function and seasonality in a captive population. Animal Reproduction Science 118 377-387. (doi:10.1016/ j.anireprosci.2009.10.001)

Hogan LA, Phillips CJC, Lisle A, Keeley T, Horsup AB, Janssen T \& Johnston SD 2010b Non-invasive methods of oestrus detection in captive Southern hairy-nosed wombats (Lasiorhinus latifrons). Animal Reproduction Science 119 293-304. (doi:10.1016/j.anireprosci.2010. 01.006)

Hogan LA, Phillips CJC, Lisle A, Horsup AB, Janssen T \& Johnston SD 2010 c Reproductive behaviour of the Southern hairy-nosed wombat (Lasiorhinus latifrons). Australian Journal of Zoology 58 350-361. (doi:10.1071/ ZO10068)

Home E 1836 Notes on the anatomy of the wombat. Proceedings of the Zoological Society of London 4 49-53. (doi:10.1111/j.1096-3642.1836. tb01363.x)

Horsup AB 2004 Recovery plan for the northern hairy-nosed wombat (Lasiorhinus krefftii) 2004-2008. Report to the Department of Environment and Heritage, Canberra. Brisbane: Environmental Protection Agency/Queensland Parks and Wildlife Service.

Hughes RL 1965 Comparative morphology of spermatozoa from five marsupial families. Australian Journal of Zoology 13 533-543. (doi:10.1071/ZO9650533)

Hughes R \& Green RH 1998 Placentation and adaptations for survival at birth in the common wombat, Vombatus ursinus. In Wombats, pp 86-108. Eds RT Wells \& PA Pridmore. Chipping Norton: Surrey Beatty and Sons.

Hughes A \& Hughes D 2006 A field observation of daytime courtship and mating in the common wombat Vombatus ursinus. Australian Mammalogy 28 115-116. (doi:10.1071/AM06017)

IUCN 2011 IUCN Red List of Threatened Species [Online]. International Union for Conservation of Nature. Access date: 17-Jan-2012. URL: www. iucnredlist.org. 
Jackson S 2003 Wombats. In Australian Mammals - Biology and Captive Management, pp 183-203. Ed S Jackson. Collingwood, Victoria, Australia: CSIRO Publishing.

Johnson CN 1991 Utilization of habitat by the northern hairy-nosed wombat, Lasiorhinus krefftii. Journal of the Zoological Society of London 225 495-507. (doi:10.1111/j.1469-7998.1991.tb03831.x)

Johnson CN \& Crossman DG 1991 Dispersal and social organization of the northern hairy-nosed wombat (Lasiorhinus krefftii). Zoological Society of London 225 605-613. (doi:10.1111/j.1469-7998.1991.tb04328.x)

Johnston SD, McGowan MR, O'Callaghan PO, Cox R, Houlden B, Haig S \& Taddeo G 2003 Birth of Koalas (Phascolarctos cinereus) at Lone Pine Koala Sanctuary following artificial insemination. International Zoo Yearbook 38 160-172. (doi:10.1111/j.1748-1090.2003.tb02076.x)

Johnston SD, MacCallum C, Blyde D, McClean R, Lisle AT \& Holt WV 2006 An investigation into the similarities and differences governing the cryopreservation success of koala (Phascolarctos cinereus: Goldfuss) and wombat (Vombatus ursinus: Shaw) spermatozoa. Cryobiology 53 218-228. (doi:10.1016/j.cryobiol.2006.06.001)

Kilen SM \& Schwartz NB 1999 Estrous cycle. In Encyclopedia of Reproduction, pp 59-79. Eds E Knobil \& JD Neill. Sydney: Academic Press.

Lin M, Harman A \& Fletcher TP 2004 Cycle of the seminiferous epithelium in a marsupial species, the brushtail possum (Trichosurus vulpecula) and estimation of its duration. Reproduction, Fertility, and Development 16 307-313. (doi:10.1071/RD02059)

MacCallum CA 2004 The reproductive biology of the common wombat (Vombatus ursinus): studies towards the development of an artificial insemination protocol. Faculty of Science (School of Animal Studies), Masters Thesis, pp 260. Gatton: The University of Queensland.

MacCallum C \& Johnston SD 2005 Studies on the cryopreservation of common wombat (Vombatus ursinus) spermatozoa. Reproduction, Fertility, and Development 17 727-732. (doi:10.1071/RD05082)

MacCallum C, Johnston SD, Ward D \& Blyde D 2001 Successful cryopreservation of common wombat (Vombatus ursinus) spermatozoa recovered from refrigerated epididymal tissue. Theriogenology 55391 (abstract). (doi:10.1016/S0093-691X(00)00457-X)

MacDonald CH, Taggart DA, Breed WG, Druery GV, Shimmin GA, Finlayson GR \& Paris MCJ 2006 Effect of exogenous gonadotrophins on ovarian morphology and oocyte maturation in the Southern hairy-nosed wombat Lasiorhinus latifrons during the breeding season. Reproduction, Fertility, and Development 18 477-484. (doi:10.1071/RD05047)

MacKenzie WC \& Owen WJ (Eds) 1919 The Genito-urinary System in Monotremes and Marsupials. Melbourne, Victoria, Australia: Jenkin, Buxton and Company.

Mallett K \& Cooke B 1986 The ecology of the common wombat in South Australia. Adelaide, Australia: Nature Conservation Society of South Australia.

Marks CA 1998 Courtship and mating in a pair of free-ranging common wombats (Vombatus ursinus). In Wombats, pp 125-128. Eds RT Wells \& PA Pridmore. Chipping Norton: Surrey Beatty and Sons.

Mcllroy J 1973 Aspects of the ecology of the common wombat, Vombatus ursinus. (Shaw, 1800). PhD Thesis. Canberra, ACT, Australia: Australian National University (Research School of Biology)

Miller RR, Sheffer CJ, Cornett CL, McClean R, MacCallum C \& Johnston SD 2004 Sperm membrane fatty acid composition in the eastern grey kangaroo (Macropus giganteus), koala (Phascolarctos cinereus) and common wombat (Vombatus ursinus) and its relationship to cold shock injury and cryopreservation success. Cryobiology 49 137-148. (doi:10.1016/j.cryobiol.2004.06.002)

Moritz K, Green RH \& Selwood L 1998 Histological analysis of the reproductive cycle of the common wombat (Vombatus ursinus). In Wombats, pp 75-85. Eds RT Wells \& PA Pridmore. Chipping Norton: Surrey Beatty and Sons.

Nicolson PJ 1963 Wombats. Timbertop Magazine 8 32-38.

O'Donoghue CH 1916 On the corpora lutea and interstitial tissue of the ovary in the Marsupialia. Quarterly Journal of Microscopic Science 61 433-479.

Oishi M, Takahashi M, Amasaki H, Janssen T \& Johnston SD 2013 The seminiferous epithelial cycle and microanatomy of the koala (Phascolarctos cinereus) and Southern hairy-nosed wombat (Lasiorhinus latifrons). Journal of Anatomy 222 380-389. (doi:10.1111/joa.12020)
Owen R 1845 Exhibition of wombat skulls. Proceedings of the Zoological Society of London 2 82-83.

Paris MC, White A, Reiss A, West M \& Schwarzenberger F 2002 Faecal progesterone metabolites and behavioural observations for the non-invasive assessment of oestrus cycles in the common wombat and Southern hairy-nosed wombat. Animal Reproduction Science $\mathbf{7 2}$ 245-257. (doi:10.1016/S0378-4320(02)00088-X)

Paris DBBP, Taggart DA, Shaw G, Temple-Smith PD \& Renfree MB 2005 Birth of pouch young after artificial insemination in the tammar wallaby (Macropus eugenii). Biology of Reproduction 72 451-459. (doi:10.1095/ biolreprod.104.033282)

Pearson J 1944 The female urogenital system of the Marsupialia with special reference to the vaginal complex. Papers and Proceedings of the RoyalSociety of Tasmania 1944 71-98.

Peters DG \& Rose RW 1979 The oestrus cycle and basal body temperature in the common wombat (Vombatus ursinus). Journal of Reproduction and Fertility 57 453-460. (doi:10.1530/jrf.0.0570453)

Phillips DJ, McKinnon A, Keeley T \& Johnston SD 2008 Testosterone secretion, testicular histology and the cryopreservation of cauda epididymidal spermatozoa in the common ringtail possum (Pseudocheirus peregrinus). Reproduction, Fertility, and Development 20 391-401. (doi:10.1071/RD07206)

Presidente PJA 1982 Common wombat (Vombatus ursinus): maintenance in captivity, blood values, infections and parasitic diseases. In The Management of Australian Mammals in Captivity, pp 133-143. Ed DD Evans. Melbourne: The Zoological Board of Victoria.

Setchell BP \& Carrick FN 1973 Spermatogenesis in some Australian marsupials. Australian Journal of Zoology 21 491-499. (doi:10.1071/ ZO9730491)

Shaw G (Ed) 1800 General Zoology or Systematic Natural History (Volume 1, Part 2, Quadrupeds). London, UK: London Publishers and Printers.

Stenke R 2002 Study of the behaviour and ecology of the northern hairynosed wombat (Lasiorhinus krefftii) at Epping Forest National Park, Unpublished internal project report for the Zoological Society for the Conservation of Species Populations. Munchen, Germany.

Taggart D, Steele VR, Schultz D, Dibben J \& Temple-Smith PD 1998 Semen collection and cryopreservation in the Southern hairy-nosed wombat Lasiorhinus latifrons: implications for conservation of the northern hairy-nosed wombat Lasiorhinus krefftii. In Wombats, pp 180-191. Eds RT Wells \& PA Pridmore. Chipping Norton: Surrey Beatty and Sons.

Taggart D, Shimmin G, Ratcliff JR, Steele VR, Dibben R, Dibben J, White A \& Temple-Smith PD 2005 Seasonal changes in the testis, accessory glands and ejaculate characteristics of the Southern hairy-nosed wombat, Lasiorhinus latifrons (Marsupialia: Vombatidae). Journal of Zoology 266 95-104. (doi:10.1017/S0952836905006722)

Taggart DA, Finlayson GR, Shimmin GA, Gover C, Dibben R, White CR, Steele VR \& Temple-Smith PD 2007 Growth and development of the Southern hairy-nosed wombat, Lasiorhinus latifrons (Vombatidae). Australian Journal of Zoology 55 309-316. (doi:10.1071/ZO07056)

Taggart DA, Schultz DJ, Fletcher TP, Friend JA, Smith IG, Breed WG \& Temple-Smith PD 2010 Cross-fostering and short-term pouch young isolation in macropodoid marsupials: implications for conservation and species management. In Macropods: the Biology of Kangaroos, Wallabies and Rat-kangaroos, pp 263-278. Eds G Coulson \& M Eldridge. Melbourne: CSIRO Publishing.

Taylor RJ 1993 Observations on the behaviour and ecology of the common wombat, Vombatus ursinus, in northeast Tasmania. Australian Mammalogy $161-7$.

Taylor AC, Horsup AB, Johnson CN, Sunnucks P \& Sherwin B 1997 Relatedness structure detected by microsatellite analysis and attempted pedigree reconstruction in an endangered marsupial, the northern hairy-nosed wombat, Lasiorhinus krefftii. Molecular Ecology 6 9-19. (doi:10.1046/j.1365-294X.1997.00146.x)

Temby ID 1993 The law and wombats in Australia. In Wombats, pp 305-311. Eds RT Wells \& PA Pridmore. Chipping Norton: Surrey Beatty and Sons.

Temple-Smith PD 1994 Comparative structure and function of marsupial spermatozoa. Reproduction, Fertility, and Development 6 421-435. (doi:10.1071/RD9940421)

Triggs B (Ed) 2009 Wombats (Second Edition). Collingwood, Victoria, Australia: CSIRO Publishing. 
Tyndale-Biscoe H \& Renfree M (Eds) 1987 Monographs on Marsupial Biology, Reproductive Physiology of Marsupials. Melbourne, Victoria, Australia: Cambridge University Press.

Walker FM, Taylor AC \& Sunnucks P 2008 Female dispersal and male kinship-based associations in Southern hairy-nosed wombats (Lasiorhinus latifrons). Molecular Ecology 17 1361-1374. (doi:10.1111/ j.1365-294X.2008.03670.x)

Wells RT 1971 Maintenance of the hairy-nosed wombat Lasiorhinus latifrons in captivity. International Zoo Yearbook 11 30-31. (doi:10. 1111/j.1748-1090.1971.tb01837.x)

Wells RT 1978 Field observations of the hairy-nosed wombat (Lasiorhinus latifrons). Australian Wildlife Research 5 299-303. (doi:10.1071/ WR9780299)

West M 2002 The oestrous cycle and manipulation of reproduction in the common wombat (Vombatus ursinus), Reproductive Sciences, $P h D$ Thesis. Victoria, Australia: Monash University.

West M, Paris MCJ, Cleary ML, Shaw J, Galloway D \& Trounson AO 2003 In vitro maturation (IVM) of oocytes collected following hormonal ovarian stimulation of common wombats (Vombatus ursinus). Theriogenology 59405 (abstract). (doi:10.1016/S0093-691X(02)01253-0)
West M, Galloway D, Shaw J, Trouson A \& Paris MCJ 2004 Oestrus cycle of the common wombat (Vombatus ursinus). Reproduction, Fertility, and Development 16 339-346. (doi:10.1071/RD03058)

West M, Lacham-Kaplan O, Cleary ML, Galloway D, Shaw G, Trounson AO \& Paris MCJ 2007 In vitro maturation and intracytoplasmic sperm injection of oocytes collected from hormonally stimulated common wombats, Vombatus ursinus. Animal Reproduction Science 98 311-321. (doi:10.1016/j.anireprosci.2006.03.005)

Wolvecamp MJC, Cleary CL, Cox SL, Shaw JM, Jenkin G \& Trounson AO 2001 Follicular development in cryopreserved common wombat ovarian tissue xenografted to nude rats. Animal Reproduction Science $\mathbf{6 5}$ 135-147. (doi:10.1016/S0378-4320(00)00228-1)

Received 14 January 2013

First decision 8 February 2013

Accepted 11 March 2013 